\title{
Geografia e complexidade pelas diferenciações areais de Hartshorne
}

Rodrigo Dutra Gomes e Antonio Carlos Vitte*

\section{Resumo}

Pretende-se dialogar algumas das proposições da Teoria da Complexidade com algumas das leituras de Hartshorne sobre o fenômeno geográfico (ontológico) e a forma de se conhecê-lo (epistemológico). Focaremos as aproximações nas noções de transformação, organizacional e complexidade. A primeira parte do artigo busca contextualizar geohistoricamente as proposições de Hartshorne e na ciência a Teoria da Complexidade. A segunda parte buscará aproximar suas considerações e a Teoria da Complexidade à partir das noções citadas. $\mathrm{O}$ objetivo é construir a relação Geografia e Complexidade, pelas aproximações teóricometodológicas, a partir dos autores reconhecidos.

Palavras-chave: Teoria da complexidade; Hartshorne; Geografia.

Geography and complexity by areal differentiation of Hartshorne

\section{Abstract}

The objective is the dialogue of some of the propositions of the Complexity Theory with some propositions of Hartshorne about the geographical phenomenon and its knowledge. The notions of uncertainty, transformation, organizational and complexity will guide the dialogue. The first part of the article seeks to contextualize geohistorically the propositions of Hartshorne and

\footnotetext{
Instituto de Geociências da UNICAMP (dutra@ige.unicamp.br) (acarlosvitte@uol.com.br).
}

Geosul, Florianópolis, v. 29, n. 57, p 89-130, jan./jun. 2014 
GOMES, R.D. \& VITTE, A.C. Geografia e complexidade pelas...

the Complexity Theory. The second part will approximate the considerations of Hartshorne and understandings precursors of the Complexity Theory based on the notions mentioned. The goal is to construct the relationship between Geography and Complexity based on the recognized authors.

Key works: Complexity theory; Hartshorne; Geography.

\section{Introdução}

Em tese apresentada em Junho de 2010 (DUTRA-GOMES, 2010, 258p.) demonstramos que é possível ler o movimento conjunto da crise da razão e matriz espacial moderna e emergência da Teoria da Complexidade sob a referência da noção de diferenciações de áreas. A pretensão na ocasião não era necessariamente a de apresentar um enfoque hartshorniano ao tratamento da relação Geografia e Complexidade, não havendo o aprofundamento da relação entre Richard Hartshorne e a Teoria da Complexidade. Contudo, em leitura mais minuciosa as congruências de sentidos encontradas entre as proposições do autor americano e a Teoria da Complexidade exigiu que a relação fosse investigada (DUTRA-GOMES, 2012, 378p.). Pretende-se aqui apresentar um diálogo de aproximação entre algumas das proposições da Teoria da Complexidade com algumas das leituras de Hartshorne sobre o fenômeno geográfico (ontológico) e a forma de se conhecê-lo (epistemológico). Focaremos as aproximações nas noções de incerteza, transformação, organizacional e Complexidade. A primeira parte do artigo busca contextualizar geohistoricamente as proposições de Hartshorne. A segunda parte buscará aproximar suas considerações e a Teoria da Complexidade à partir das noções citadas. Ainda não pretendeu-se utilizar, ou construir, um enfoque hartshorniano, pretende-se mais é construir a relação Geografia e Complexidade pelas aproximações teóricometodológicas a partir dos autores conhecidos - como, por exemplo, fez Carvalho (2008). 
GOMES, R.D. \& VITTE, A.C. Geografia e complexidade pelas...

Com seus estudos e escritos inseridos no contexto de aprofundamento da crise da razão e matriz espacial, a partir da década de 30, as considerações de Hartshorne deixam transparecer a influência desse movimento da crise da razão, matriz espacial e emergencia da Teoria da Complexidade. Mas é importante já de início destacar que Hartshorne nunca se propôs a discutir Filosofia da Ciência, nem a sua relação com a Geografia, ou desta com aquela. $\mathrm{O}$ seu questionamento não era ontológico, sobre novas formas de se conceber o 'funcionamento' do mundo, mas sim epistemológico sobre a Geografia, e suas problemáticas e ambiguidades internas do período. Assim, quando nas citações usadas Hartshorne utilizar o termo 'complexidade', ou 'incertezas', é necessário considerar que ele não estará se referindo diretamente ao contexto da Teoria da Complexidade. $\mathrm{O}$ que faremos é buscar em seus argumentos sobre a história e epistemologia da Geografia, e que traz embutido a sua concepção de diferenciação de áreas, os sentidos implícitos e explícitos de ontologia e epistemologia, e com elas dialogar com os entendimentos e noções da Teoria da Complexidade.

Nesta direção, parece mesmo nele ocorrer o questionamento e a consciência do caráter não absoluto dos preceitos universais da Ciência, influenciado tanto pela sua postura pragmatista, quanto pelas movimentações na ciência e sociedade no início do século XX. Na Geografia, mesmo se implicitamente, parece atribuir propriedades epistemológicas e ontológicas para as diferenciações, e que decorrerá num discurso de natureza e realidade enquanto multiplicidade - de variações fenomenais (ontologia) e pontos de vistas de análise (epistemologia). Se assim for, em sua leitura epistemológica da Geografia moderna e da noção de diferenciação de áreas antecipa, então, vários argumentos ontológicos e epistemológicos que a Teoria da Complexidade, e diversos textos contemporâneos, vieram depois, no âmbito científico, confirmar a sua legitimidade.

Exploraremos essa relação, dialogando os sentidos das principais noções associadas à Teoria da Complexidade (as incertezas, transformações, organizacional e complexidade) com as considerações de Hartshorne, tendo as diferenciações de áreas 
GOMES, R.D. \& VITTE, A.C. Geografia e complexidade pelas...

como baliza - isso como forma de ampliar o arcabouço epistemológico do conceito e da disciplina, além servir de mediação para incrementar o pensamento e aplicação dos modelos.

Hartshorne recorreu à noção de diferenciações de áreas para auxiliá-lo na resposta à pergunta da ocasião - qual a natureza do estudo da Geografia? - e que reconheceria e esclareceria as ambiguidades, dualismos e incomunicabilidades que perturbavam a disciplina na década de 30. É interessante observar que ao procurar ser uma ciência universal, participando de um conhecimento dito como universal, a Geografia na modernidade afirmou-se, via Hartshorne, tratando-se de diferenças como objeto de estudo. A Teoria da Complexidade afirma agora no início do século XXI que a Ciência trata fundamentalmente de fenômenos espaçotemporalmente localizados, ou seja, de diferenças (PRIGOGINE, 1996, SCIENCE, 1999). Para a Geografia a Complexidade destaca a situação de particularidades históricogeográficas para os fenômenos geográficos (PORTUGALI, 2006, MANSON \& SULLIVAN, 2006). Acompanhando o reconhecimento do caráter complexo da realidade, a noção de diferenciações de áreas torna-se novamente pertinente para dialogar com a nova situação, já que confirma-se no plano epistemológico e ontológico, o que, no período de sua formulação, fora motivo de embaraços (HARTSHORNE, 1978, p.13): não só a Geografia, mas a Ciência em geral, mesmo podendo buscar regras, reconhece-se tratando, agora, fundamentalmente de diferenças, de particularidades históricogeográficas, de diferenciação de áreas.

\section{O contexto das proposições hartshornianas: as diferenciações de áreas depois da primeira guerra mundial}

A profunda depressão econômica pós-1a guerra foi seguida, nos Estados Unidos, de uma fase de prosperidade na década de 20. A sociedade americana foi a primeira sociedade de consumo de massa, com todas as suas virtudes e defeitos, trinta anos antes que os outros países atingisse esse nível. Durante largo período de tempo os EUA já vinham desfrutando de alimentos com baixo custo, relativa escassez 
GOMES, R.D. \& VITTE, A.C. Geografia e complexidade pelas...

de mão-de-obra, tornando constante a oferta de empregos, e amplo mercado consumidor; ou seja, a importância do consumidor não necessariamente foi maior na economia daquela época do que havia sido antes. A diferença básica a partir da década de 20 é que os principais produtos de consumo eram diferentes de anteriormente, já sendo, mais ou menos, os mesmos produtos consumidos pelo mundo na década de 70. Com a implantação do sistema fordista de produção e montagem, certos produtos como rádios, eletrodomésticos, além dos automóveis, começaram a serem produzidos em grande escala e baixos preços. A demanda produtiva de produtos como os automóveis fomentou a demanda de produtos complementares como pneumáticos, metalurgia etc. Os níveis de venda se mantiveram pela ampliação da propaganda e publicidade em rádios. De acordo com Adams (1979, p. 257) naquela época nenhum outro país, nem remotamente, conseguiria alcançar esta situação econômica; os Europeus observavam a expansão americana com uma mistura de incredulidade, admiração e inveja. Assim, o sentido de intensificação da compressão da experiência espaçotemporal em direção à globalização do final do século foi vivida inicialmente, primeiramente, neste país. Em nenhum outro país do período o sentido da universalização do tempo e esvaziamento do espaço, pela expansão do capitalismo, seguiu tanto o seu sentido prático; caracterizando, também o forte sentido pragmático da conduta americana, que será comentado a seguir em Hartshorne. Num movimento antagônico e complementar o sentido de esvaziamento do espaço para a expansão do capital novamente requereu a necessidade de se conhecer as particularidades das áreas à serem exploradas, como forma mesmo de adequadamente favorecer essa expansão.

Neste período, enquando na Ciência a Teoria da Relatividade de Einstein, nobel em 1921, expandia as repercussões de um espaço relativo e diferenciando pelos corpos, pela geografia americana tornou-se essencial o conhecimento das diferenciações espaciais para a recuperação e expansão da economia. Este foi um período de intensos trabalhos de inventários de recursos, classificação de áreas e formas de uso do terreno. Vários métodos de classificação, bem como, 
GOMES, R.D. \& VITTE, A.C. Geografia e complexidade pelas...

planos de gestão foram propostos. Envolvendo o engajamento de orgão públicos como Comitê Nacional de Planejamento de Recursos, Departamentos Regionais de Estudos de Planejamento, Comitê de Recursos Hídricos etc, os métodos e práticas de campo, ganharam aliados técnicos como as fotografias aéreas na década de 30, possibilitando, por exemplo, no plano de mapeamento, a experimentação de diferentes escalas para a representação, de acordo com a complexidade do quadro natural e humano, e dos interesses de utilização, econômicas por exemplo. Convergente com a expansão internacionalista, esses inventários não eram somente do território nacional, mas de regiões do mundo. Cita-se, por exemplo, em contexto regional, a elaboração do mapa a milionésimo da América Hispânica. Soma-se a experiência e trabalhos de Bowman no Peru, Guatemala e Honduras que clarificou o problema da falta de informações à respeito destas áreas, incentivando o mapeamento da América Latina como um todo. Inviabilizado pelos possíveis gastos e demora de junção do material, Bowman sabia que muitas informações já haviam sido geradas por órgãos públicos ou privados para diversos propósitos. Ele propõe, então, que a Sociedade Americana de Geógrafos se engajasse no maior programa de pesquisa para a compilação de um mapa realizado até então. Fez diversos contatos com os institutos e associações dos países e empresas para a cooperação e troca de informações disponíveis. O projeto iniciou-se em 1920 e completou-se em 1946 (JAMES, 1972).

Outra aplicação característica das décadas de 20 e 30 na Geografia Americana foi a busca pela solução de problemas práticos relacionados as formas de uso e gestão da superfície e recursos. Havia-se percebido que além do reconhecimento das informações sobre os recursos disponíveis era necessário elaborar planos de gestão e guia com vista evitar a degradação predatória e insustentável, já notável em certas regiões na época. Uma das questões era fornecer elementos para que os interesses privados não viesse à degradar os recursos. Os esforços de classificação das áreas e usos potenciais já eram feitos no período da independência dos Estados Unidos quando ocorrera a necessidade de se expandir as informações do recursos para 
GOMES, R.D. \& VITTE, A.C. Geografia e complexidade pelas...

o Oeste. Agora a necessidade é de otimizar o uso econômico com respeito à quantidade de área e de produtos produzidos, sem que para isso os recursos naturais sejam exauridos. Um dos trabalhos conhecidos foi o estudo realizado em Michigan com a elaboração de classificações em geral e o estabelecimento de classes potenciais de uso econômico da área, cujos resultados serviram para planos de gerenciamento estendíveis para as regiões vizinhas na década de 30 (JAMES, 1972). Sobre essa consciência 'regionalista' convém lembrar que até a arte, como nas pinturas de Thomas Benton, destacava-se o tema regionalistico nas particularidades das propriedades rurais, ainda predominantes na época.

Na movimentada situação de trabalhos práticos no pós Primeira Guerra Mundial gerou-se um período de mudanças conceituais advinda da variedade de idéias surgidas experimentalmente. Houve, de uma forma geral, uma gradual erosão de conceitos ligados à controles físicos e respostas humanas como pregados pelo determinismo ambientalista, e uma vigorosa competição para novas abordagens para o inquérito geográfico, como a Ecologia Humana de Harlan Barrows, a Morfologia da Paisagem de Carl Sauer. Apesar de ter utilização prática para fins estratégicos em geral, essa diversidade não trouxe para a Geografia o prestígio que ela havia conquistado na segunda metade do século XIX. Assim, depois dessa fase de rápido crescimento, a disciplina se estabiliza. Aplica nesta fase inicial do século os conhecimentos elaborados na grande mutação que houve nos últimos trinta anos do XIX, contudo, houve embaraços pela falta de uma base teórica de todos os desenvolvimentos que se seguiu desde este período. Assim, a Geografia hesitou entre a concepção regional, a análise da relação entre o homem e o meio, e os estudos das paisagens. Mas, buscando a adequação ao conhecimento moderno e desejando ser respeitável, a Geografia, mesmo os possibilistas, buscou trabalhar dentro de uma prática característica das ciências naturais, se afastando das questões sociais, ou mesmo não a abordando de forma mais direta (CLAVAL, 1984, p.55).

O capital, num movimento orgânico, também como o conhecimento e a arte, se alimentam de crises. Assim, no movimento 
GOMES, R.D. \& VITTE, A.C. Geografia e complexidade pelas...

da crise da matriz espacial, a tensão entre o universal e o particular, em território norteamericano na década de 30, expressou-se geograficamente pela tensão entre a expansão interna sem igual das concepções universais dos costumes ocidentais e capitalistas e a necessidade de aprender e gerenciar as características singulares dos lugares do seu próprio território e de outros países para fins estratégicos de gerenciamente para superação da depressão, quanto de expansão de suas 'fronteiras' financeiras pelas diversas áreas. Como conhecimento, a Geografia tanto buscava afirmar seu caráter de ciência singular e prática, e adequar-se à ciência universal, quanto corroía-se internamente na tensão entre a diversidade incomunicante de abordagens. Se, por um lado, serviu como uma útil ferramenta para a expansão universal do capital, pelos inventarios de recursos e características particulares de áreas internas e exteriores, ou seja, universalizando a particularidade das áreas, por outro lado, com a perda da hegemonia e o questionamento da racionalidade positivista e a desagregação do projeto geográfico universalista, as antigas certezas que traziam enquanto conhecimento rigoroso deram lugar a uma certa insegurança e desacordo entre essas diferentes perspectivas que animavam à crescente diversidade e heterogeneidade conceitual e metodológica. Somada à crescente especialização no âmbito científico derivaram-se muitas das dificuldades e questionamentos que movimentaram, em resposta, discussões e proposições que se esforçavam para salvaguardar a objetividade, unidade teórica, metodológica e identidade da Geografia junto aos outros campos.

Richard Hartshorne insere-se neste movimento como umas das importantes proposições deste projeto de reconciliação do saber geográfico com a segurança de ser uma ciência generalista, unitária e singular, ainda em torno do conceito de região. A noção de diferenciação de áreas vem então como emergida das interpretações dos seus trabalhos sobre a conduta da Geografia na modernidade; e que, pela tese aqui seguida, expressava o movimento da crise da relação entre o universal e o particular na matriz espacial, com a Geografia buscando sempre superar essa situação. Nela podemos observar claras influências, citadas por 
GOMES, R.D. \& VITTE, A.C. Geografia e complexidade pelas...

Hartshorne, e que exploraremos ao longo do capítulo, das mudanças epistemológicas trazidas pela ciência e filosofia do início do século $\mathrm{XX}$, numa leitura pragmatistas, com argumentos que antecipavam aspectos primordiais de repercussão da incorporação da Teoria da Complexidade na Geografia.

Hartshorne foi formado e trabalhou no típico rigor da filosofia pragmatista da universidade americana (HARVEY \& WARDENGA, 2006, p.429). Seu irmão, Charles Hartshorne, foi um renomado filósofo do pragmatismo e leitor de Whitehead, e que sob esta influencia fraterna fez, de acordo com Hepple (2008, p.1539), o geógrafo deter uma postura mais funcionalista que a concepção alemã de Hettner. Inicia seus trabalhos acabêmicos em Minnesota em 1924, com pesquisas ligadas à Geografia Política, à Sistemas de Transporte, e fatores de Localização em Geografia por exemplo, como estes fatores afetavam as Industrias. Ele foi, aparentemente, o primeiro a salientar que os custos de transporte foram fundamentais na localização da indústria do ferro e aço americana. No contexto da depressão econômica de 1930 realça-se que estudos de Hartshorne insere-se no período de promulgação do primeiro (1933-1935) e segundo (1935-1941) New Deal, justamente em resposta à essa situação (JAMES, 1972). Em 1931 1932, durante os anos de recessão, e elaboração dos teoremas da incompletude de Gödel, que pôs fim as pretensões universais da matemática, Hartshorne foi premiado com uma bolsa pelo Social Science Research Council, o que lhe permitiu viajar para a Europa para estudar os limites políticos do velho continente, com especial referência ao antigo Império Alemão. Seus conhecimentos de língua alemã melhorou muito depois que ele passou a trabalhar nesse meio, e que foi essencial para a sua posterior leitura em alemão dos geógrafos alemães (Kant, Humboldt, Hettner etc).

Sobre os pressupostos do conhecimento, adequando a Geografia à uma leitura pragmatista, e se utilizando do método empírico-indutivo do Circulo de Viena, Hartshorne seguia um sentido diferente de naturalismo e objetivismo em relação aos neopositivistas. Seus trabalhos em Geografia Política e fatores de localização, ligado a 
GOMES, R.D. \& VITTE, A.C. Geografia e complexidade pelas...

um contexto de engajamento planificado do Estado para a recuperação da depressão economica, trouxe uma carga de funcionalidade às suas leituras e interpretações, realçando uma forte consciência sobre os 'interesses relativos' e variados de poder e gestão, e que claramente, por um lado, negava, na prática, o princípio de neutralidade e objetividade absoluta dos neopositivistas. Não se quer dizer que as atitudes de Hartshorne eram politicamente dirigidas à favor de imperialismos e burocracias, e neste sentido, temos aqueles que, como Campbell (1994), o chamam de Humanista, mas principalmente que, além do neopositivismo-naturalismo, representantes dos "fins de razão infinitos", suas condutas entram em maior concordância com a filosofia pragmatista (HEPPLE, 2008). Influenciada inclusive por seu irmão, o pragmatismo baseia-se basicamente, na noção de utilidade, laborabilidade, e praticabilidade das ideias, propostas e politicas como critérios para o mérito de verdade. Nela a ação pratica detém prioridade sobre a doutrina metafisica, e a experiencia em relação aos principios fixos absolutos; o que muito influenciou Hartshorne na proposta das diferenciações de áreas como uma leitura da noção de região, mas tendo como ponto de vista, preceitos científicos nãoabsolutos e a referência relativa do observador. Em relação à isso temos também a influência do contexto de reflexão na ciência trazido pela Teoria da Relatividade, física quantica, incompletudes lógicoformais etc e que, como veremos, Hartshorne (1978) remete em relação as 'incertezas' do conhecimento, transparecendo, nele o peso do contexto que passou, nos termos de Bachelard (1977, 31-36), da objetividade (absoluta) à objetivação (relativa) na conduta científica; prelúdios do pensamento complexo.

Foi neste período a partir de 30 que Hartshorne começou a se tornar cada vez mais preocupado com as indefinições e ambiguidades epistemológicas do campo. Com o choques que ocorriam nas reuniões anuais da Associação Americana entre as quatro correntes praticadas fisiografia Davisiana, o estudo do determinismo ambiental, a geografia cultural emergente, e a ecologia humana - Hartshorne sentia que se tornava cada vez mais necessário uma compreensão clara da natureza e propósito da geografia como condição essencial para um 
GOMES, R.D. \& VITTE, A.C. Geografia e complexidade pelas...

adequado e seguro estudo geográfico. Estava desconfortável com as declarações de Sauer sobre a natureza do fato geográfico e buscava revisar o ponto de vista oferecido por este (Sauer) da Geografia alemã, que era feita com base em Siegfried Passarge e Schluter Otto. Hartshorne advertia que Sauer, sob estas bases, excluía do campo geográfico a Geografia Política, por ele praticada. Nestes termos a conhecida influência a partir de Hettner se realça também pela presença política em seus escritos e que fez Hartshorne considerá-lo um tanto mais claro e lógico do que Passarge e Otto (MARTIN, 1994, p. 483-484). Paralelamente houve a discussão que se estabeleceu com John Leighly em 1937, que advogava que nenhuma teoria poderia ser encontrada na heterogeneidade do fenômeno geográfico, e que de acordo com Hartshorne esterelizava o campo geográfico ao torná-lo apenas de caráter descritivo. Leighly entregou artigo para publicação no Annais da Associação Americana de Geografos à Robert Platt, e que contrastava com as leituras de Hartshorne de Geografia Regional. Robert Platt sugeriu que Hartshorne respondesse a Leighly com outro artigo, e que acabou dando origem, depois de ser ampliado, ao 'The Nature of Geography" em 1939 (LUKERMANN, 1989, p.54), com Hatshorne buscando esclarecer e resolver, a partir de uma leitura sua da história da disciplina, as situações de conflito e ambiguidades metodológicas que se desenhavam na geografia americana da época.

O The Nature foi publicado pela Associação Americana de Geógrafos e tornou-se um dos textos mais lidos pelos geógrafos alunos e professores do período. Foi traduzido em diversas línguas, e mesmo com a paralização nas reflexões causado pela situação e afazeres da $2 \mathrm{a}$ Guerra Mundial, o texto continuou tornando-se, depois do evento, fundamental para quem quisesse entender as dimensões da Geografia. Com citação de autores britânicos, franceses, suecos e principalmente os alemães, Hartshone buscou apresentar o caminho que os geógrafos de renome tinham trilhado e a impressão que haviam deixado sobre as caracteristicas da disciplina. Seu propósito de acordo com Martin (1994) foi a de oferecer uma abordagem para os problemas metodológicos que os geógrafos dos períodos anteriores tinham confrontados e para estabelecer uma estrutura de entendimento do 
GOMES, R.D. \& VITTE, A.C. Geografia e complexidade pelas...

crescimento da disciplina. Posteriormente declarou que a sua intenção era estabelecer 'a logically sound structure of the nature of geography' and 'determine the actual character of geographic work' (HARTSHORNE, 1959). Vinte anos após o 'The Nature' Hartshorne publica o Perspective in Geography (1959) onde, com base em reflexão e discussão busca estender, resumir e elaborar conclusões, acompanhando e incrementando os entendimentos do trabalho original.

Contudo, devido à emergência da Revolução Quantitativa e Teorética, os geógrafos treinados em modelagem nos laboratórios da Segunda Guerra (BARNES, 2006, 2008) elegeram o discurso de Fred K. Schaefer, em seu famoso artigo (SCHAEFER, 1953), a favor da abordagem nomotética, como substituta a uma histórica tendência idiográfica considerada defasada, "velha", para as demandas então urgentes da "idade de ouro dos países industrializados". Schaefer morre antes mesmo de sua crítica aos 'excepcionalismos de conduta' ser publicada. Hartshorne fica sem ter com quem dialogar diretamente. De imediato responde com meticulosidade o artigo de Schaefer refutando os argumentos de parágrafo a parágrafo (HARTSHORNE, 1955). Este debate causou uma certa divisão na geografia norte-americana com certa hegemonia da Nova Geografia pautada em modelos. Isso deixou Hartshorne perturbado pelos poucos debates de resposta e a constante afirmação que nunca advogou a favor da predominância de nenhuma abordagem e sim a sua fluidez, com a "geografia tanto precisando de estudos genéricos quanto de estudos de casos individuais" (HARTSHORNE, 1978, p.174), o que, para ele, não impedia os modelos estatísticos e teorias de desempenharem seus papeis (HARTSHORNE, 1978, p.171); embora, a hegemonia unilateral de uma abordagem, a nomotética ou idiográfica, poderia também esterilizar o campo. Mas aspectos como a manifestação singular do fato geográfico, e a necessidade da Geografia lhe dar com ela, com as diferenciações espaciais, era uma constante que observou nos diversos autores $\mathrm{e}$ ao longo de todo o desenvolvimento da disciplina e que continuara a afirmar no Perspective in Geography publicado em 1969, trinta anos depois 
GOMES, R.D. \& VITTE, A.C. Geografia e complexidade pelas...

(HARTSHORNE, 1978, p.16, p.168). Em sua abordagem discutindo as diferenciações areais e decorrências epistemológicas, antevê o objeto de discussão dos geógrafos no final do século XX nas primeiras leituras da relação Geografia e Complexidade.

Hartshorne, na ocasião, apresentou a ideia de diferenciações de áreas como sintetização da consideração de diversos autores para caracterizar a natureza do estudo da Geografia moderna. Em seu argumento organiza as considerações feitas, via leitura neokantiana de Hettner, por Richthoffen dos pontos de vista de Humboldt e Ritter sobre a natureza da Geografia. Richthofen colocava de forma mais direta que "a geografia era o estudo da superfície da terra conforme suas diferenças, ou o estudo das diferenciações de áreas (...) em termos de suas características totais (HATSHORNE, 1978, p.182). Já Hettner partiu do princípio de que historicamente a (...) matéria específica da Geografia (...) consistiu no conhecimento das áreas da terra na medida em que diferiam umas das outras; com o homem sendo parte integrante da natureza de uma área; e devido ao avanço da Ciência ampliara-se do foco nas descrições pela busca de causas no estudo das áreas (HARTSHORNE, 1978, p.14). Em sua análise específica Hartshorne buscou (1978, p.13) afastar as dúvidas e ambiguidades de interpretação do sentido da Geografia enquanto estudo das diferenciações de áreas, e concluíra de que para evitar incompreensões, tornaria-se mais adequado substituir o termo diferenças por variações. A Geografia teria (...) por objeto proporcionar a descrição e a interpretação, de maneira precisa, ordenada e racional, do caráter variável da superfície da terra (HARTSHORNE, 1978, p.22).

Com sua leitura pragmatista do caráter variável da superfície, as diferenciações de áreas deixam de ser algo a ser 'encontrado', como que se estivessem "localizadas" no espaço, para ser algo a ser construídas pelo 'olhar do pesquisador' em acordo a determinados objetivos (Hartshorne, 1978). Nestes termos, o olhar do pesquisador poderia ser, tanto do cientista acadêmico, como do governo dos EUA, do Pentágono, da CIA, das multinacionais etc. 
GOMES, R.D. \& VITTE, A.C. Geografia e complexidade pelas...

Na ciência a emergência do contexto da complexidade

$\mathrm{Na}$ ciência a relativização da estrutura espaçotemporal, a teoria quântica e teorias sistêmicas são uma das principais representantes, na primeira metade do século $\mathrm{XX}$, do reconhecimento do caráter processual da realidade e do conhecimento. Em prosseguimento, a segunda metade do século corroborou essa processualidade e reconheceu, em campos como os Sistemas dinâmicos não-lineares e Física do não-equilíbrio, o caráter fundamentalmente complexo dos sistemas da natureza, inseridos numa perspectiva organizacional. Complexo no sentido de apresentar uma infinita gama de interrelações entre entidades e dimensões, com emergências de estruturas, com presença, em par com a determinação, de dinâmicas imprevisíveis a curto e longo prazo, que incluem a possibilidade da matéria se auto-organizar de níveis mais simples para mais complexos, como nós, animais culturalmente humanos. Na dinâmica da matéria e do ser vivo, reconhece-se a existência de multi-domínios e dimensões mutuamente influentes e generativas, mas não redutíveis uns aos outros. O particular, o contingente que buscou ser dominado apresenta-se como fator primordial para o dinamismo criativo da natureza (PRIGOGINE, 1989). Ocorre a necessidade de um novo sentido para o universal. A questão ontológica e epistemológica se realça. Os dualismos dicotômicos tornam-se fluidos, interconectados, mutuamente, generativos e interatuantes. Os sistemas da natureza são reconhecidos como detendo um caráter fundamentalmente espaçotemporalmente localizados, se expressando sempre de forma singular às interações que estabelece consigo mesmo e o ambiente. Diferente da concepção simétrica e a-histórica moderna os sistemas (de relações) da natureza detém sua própria historicidade, temporalidade, ou seja, são únicos, dos átomos às galáxias; o espaço apresenta-se como a coexistência da multiplicidade, das diferenças. Além das novas técnicas trazidas, a consciência da Complexidade é a dos limites do conhecimento (MORIN, 1985). Convergente com o pós-moderno, esclarece a impossibilidade das pretensões monísticas e das metanarrativas. As perspectivas são de diálogo entre as formas de 
GOMES, R.D. \& VITTE, A.C. Geografia e complexidade pelas...

conhecimentos aplicadas expressas em termos duais:
explanativo/interpretativo,
ciências/humanidades. A busca é de novas proposições e
reconceituações, ou 'terceiras', para além do dual Conectada à
Geografia esse contexto, serve de apoio para o vislumbre de uma Nova Cognição do Sistema Terra-Mundo, com a possibilidade de reestruturação do projeto de humanidade iluminista, tendo agora como referência o aporte espacial, ainda que não em exclusão ao temporal, ao histórico (DUTRA GOMES, 2010, 151-176 e 185).

Os entendimentos da Complexidade já estão sendo incorporados na ciência em geral e Geografia principalmente a partir do final do século XX e início do XXI, trazendo importantes repercussões nos diversos campos (SCIENCE, 1999, 1-212, MALANSON, 1999, p.746-753). Numa perspectiva de ultrapassagem da matriz espacial moderna o próprio espaço pode ser considerado como um processo auto-organizado (SMØLIN, 2003, p.1081-1088). $\mathrm{Na}$ Geografia, neste vislumbre reconhece-se o caráter fundamental de particularidades histórico-geográficas dos fenômenos geográficos. As dualidades e fundos dicotômicos persistentes se dissolvem e fluem numa perspectiva organizacional, sem perder suas distinções e legitimidades. A construção do espaço geográfico, neste contexto, independente das diversas definições, se dá por multi-domínios e dimensões, mutuamente influentes e generativos, mas que não são redutíveis nem em manifestação (ontológico), nem em entendimento (epistemológico) uns aos outros, exigindo, a necessidade de dialogar com outras formas de conhecimento (DUTRA GOMES, 2009, p.119). As incertezas ontológicas e epistemologicamente reconhecidas tornam-se uma das brechas de abertura para que, a partir dos modelos, ocorra esse diálogo entre perspectivas. A dualidade Espaço e Lugar tornam-se duas formas de compressão de informação no interior da caixa craniana do sujeito. $\mathrm{O}$ ato de distinção e indicação entre espaço/lugar, nomotético/idiográfico, ciências/humanidades etc, tornam-se inescapáveis de um ponto de vista cognitivo. Disso extraise que não convém mais, a não ser de forma limitada e reduzida, os sistemas espaciais pautarem sua investigação apenas em uma singular 
GOMES, R.D. \& VITTE, A.C. Geografia e complexidade pelas...

estrutura explanatória para todas as escalas e domínios relevantes para a sua manifestação total. Sob a referência da auto-reflexividade do sujeito, reconhece-se a necessidade de se respeitar e aceitar as diversas coerências cognitivas das diversas pessoas, e explicativas, sobre as formas de conhecimento praticadas, como as epistemologias, métodos, culturas, misticismo etc. O panorama é de diálogos e comunhões entre as formas de conhecimentos antes pautadas no dual, e busca de terceiras proposições. Estabelece-se uma tensão criativa de diálogos e comunhões entre explanativo/interpretativo, ciências/humanidades (DUTRA GOMES, 2010, 219-230).

\section{Aproximações entre a incerteza científica e proposições de Hartshorne}

Se o projeto científico moderno aspirava um conhecimento direcionado à certeza do funcionamento e causas do mundo, e que isso refletiria um mundo ordenado e estático segundo leis fundamentais, e que por determinado por elas, seria incapaz de 'surgir' ou 'criar' novas coisas, o seu próprio aprofundamento tanto no XIX, mas principalmente no XX, reconheceu as incertezas, as transformações, o organizacional criativo, a complexidade, como inerente ao mundo e ao conhecer. Iniciaremos o argumento com as repercussões advindos da ciência a partir do eletromagnetismo, termodinâmica do XIX e da Teoria da Relatividade, Teoria Quântica e contexto político-econômico, pois esses eram as principais referências contextuais no momento dos principais escritos de Hartshorne As repercussões na disciplina na Geografia e os argumentos de Hartshorne, atrelados à noção de diferenciação de áreas, serão localizados ao longo do texto no diálogo com os principais entendimentos do contexto.

Nas Ciências físicas, tidas como modelo de ciência universal-absoluta, as incertezas já se faziam presentes ainda no XIX com Maxwell (1831-1879), na eletrodinâmica. Observou ele que havia em sistemas físicos, cuja noção de 'campo' seria pertinente, comportamentos imprevisíveis que poderiam evoluir de 
GOMES, R.D. \& VITTE, A.C. Geografia e complexidade pelas...

pequenos para grandes efeitos (MOREIRA, 1995, p.40-45). A ideia de campo eletromagnético, e suas incertezas associadas, repercutiram em Kant e nos românticos, como Schelling e Goethe, na transição da concepção mecânica para uma orgânica de Natureza. Auxiliou a retomada das abordagens holísticas em realce à ideia de 'todos organizados' que Humboldt e Ritter muito bem se aproveitaram (MEYER-ABICH, 1962, p.140), por exemplo, pela noção de região para universalizar as incertezas e particularidades espaciais encontradas na superfície da terra; primeiras composições do que decorreria nas diferenciações de áreas.

Logo em seguida a Termodinâmica foi uma das primeiras que inseriu, com o termo entropia, o sentido de evolução, transformação, incerteza e desordem na descrição determinística científica moderna - lhe dando com probabilidades de trocas e dissipação. A entropia mede o grau de evolução-transformação energética de um sistema, sempre indo, unidirecionalmente, de um estado potencial (ordem) para um estado dissipado (desordem), podendo assim, também ser visto como uma medida de desordem e degradação do sistema. Coloca também um sentido de Flecha unidirecional - potencial-dissipado - para o Tempo, e que repercutiu em filósofos como Henri Bergson. Novamente aparece na universalização das diferenças areais, principalmente no sentido evolutivo, por exemplo, em Ratzel e W. M. Davis, com o primeiro pela influência na evolução 'hologéica' da relação homem e ambiente, e o segundo no Ciclo evolutivo da Erosão na Geomorfologia (ABREU, 2003).

No caso de Ratzel, convém lembrar que a teoria da evolução de Darwin coloca um significativo papel às aleatoriedades, à incerteza do acaso, como importante fator a se considerar na mutação para a evolução biológica. Convém lembrar que o Darwinismo, em sua versão Social, foi utilizado aqui no Brasil em autores como Silvio Romero, Oliveira Vianna e Euclides da Cunha que visavam promover o progresso para o território nacional. No caso de Euclides, defendia uma visão nacionalista, que afirmava a miscigenação como singularidade, com os mecanismos espaciais 
GOMES, R.D. \& VITTE, A.C. Geografia e complexidade pelas...

de transporte e produção devendo servir para a interligação interna das regiões de forma a proporcionar a unidade territorial do país e seu progresso próprio (ANSELMO \& BRAY, 2001). Dessa forma, foi usado, por Euclides, para afirmar a particularidade Brasil frente à universalidade dos costumes e padrões europeus.

Soma-se a este contexto de proposições trabalhos como o de H. Poincaré que também demonstrou a existência de instabilidade no estudo da interação de corpos celestes, não encontrando uma solução analítica estável para a equação que buscava harmonia e equilíbrio de forças entre três corpos em interação gravitacional newtoniana - o Sol, a Terra e a Lua, por exemplo; as equações divergiam, respondendo que o sistema se tornava errático e imprevisível com o passar do tempo e interações (BERGÉ et. al, 1996, p.262).

Apesar dos questionamentos, naquela situação, sob hegemonia do paradigma newtoniano, as dificuldades encontradas por Maxwell, pela termodinâmica, Poincaré, e também pela química, biologia etc foram tratados, na Ciência, como, no máximo, curiosos problemas, uma limitação descritiva provisória, vista como algo apenas aparente e não fundamental. Ou seja, o paradigma vigente não relevou ou se conscientizou, mas submeteu as contingências, incertezas, particularidades encontradas à racionalidade universalista, que afirmava a lei, a regra, a estabilidade, o equilíbrio como fundamentais no funcionamento do mundo; e que também vinha obtendo expressivos resultados no contexto da Segunda Revolução Industrial. Na Geografia as diferenciações espaciais, sejam políticas ou naturais, saltavam cada vez mais aos olhos, por exemplo, com as guerras territoriais européias e americanas e as grandes expedições continentais que traziam à consciência as diversidades morfodinâmicas, ecológicas e culturais das diversas regiões do planeta; com a Geografia universalizando estas diferenciações espaciais pelas diversas formas, e relativa (diferente) aos diversos contextos e interesses nacionais (franceses-regionalistas, alemães-deterministasnaturalistas, anglo-saxões-pragmatistas etc). 
GOMES, R.D. \& VITTE, A.C. Geografia e complexidade pelas...

Na primeira metade do século XX, nas ciências físicas, a Teoria da Relatividade e a física quântica trouxeram elementos experimentais e epistemológicos que colocaram as incertezas mais perto do conhecimento científico. Além de firmar uma concepção relativa e quadridimensional do espaçotempo, ao representar o questionamento humano em relação às suas próprias estruturas de pensamento, a Relatividade fixa a insegurança, pois, a construção denominada Ciência bem poderia estar a falar menos a respeito do mundo do que a forma como espírito o concebe. A incerteza se estabelece não somente no sentido físico, pela limitação espaçotemporal do conhecimento, que torna a universalização para todo o universo incerta, mas também das novas possibilidades de interpretação da aceitação, organização e evolução passada e da construção das futuras teorias e paradigmas científicos. Nenhuma teoria da ciência poderia mais se impor como absolutamente objetiva (JAPIASSU, 1981). Reconhece-se que a ciência é uma construção, uma criação humana (BACHELARD, 1977). A evolução do conhecimento iluminista, voltado à certeza e direcionado para a verdade, dá lugar à incerteza da possibilidade de construção do conhecimento; e que influenciou autores como Ortega y Gasset com o seu perspectivismo: "esta suposta realidade única e imutável... não existe: o que existe são muitas realidades como pontos de vistas"... "agora a perspectiva é aperfeiçoada pela multiplicação de pontos de vista"... "não existe espaço absoluto porque não existe perspectiva absoluta. A teoria de Einstein é uma prova da harmoniosa multiplicidade de todos os pontos de vistas possíveis"(KERN, 1983, p.151). Nesta situação, com respeito ao planejamento do espaço, a racionalidade não precisava mais significar uma perspectiva linear, pois novos sentidos de relativismos e perspectivismos poderiam ser inventados e aplicados à produção do espaço e à ordenação do tempo (HARVEY, 1992, p.246). Antes de comentarmos as influências vividas na Geografia e Hartshorne, comentemos a incerteza política da época e apresentemos a 'relativização', e a incerteza, no nível fundamental da matéria.

No contexto político-econômico a vivência mais nítida de um espaço relativo, e o sentimento de incerteza no imaginário das 
GOMES, R.D. \& VITTE, A.C. Geografia e complexidade pelas...

pessoas, se expressou pela explosão da Primeira Guerra Mundial, em Julho de 1914, que proveio, dentre outras pela intensa compressão espaçotemporal (HARVEY, 1992, KERN, 1992) trazida pela experiência geográfica com o globalismo do início do século. Outro aspecto marcante da consciência de um espaço relativo, e de incertezas em relação ao futuro veio da Revolução Russa em 1917. Sob o sentimento de ruptura que se estabeleceu pôde ela florescer como filha da la guerra, como uma nova perspectiva, para novamente se referir a Ortega y Gasset, para a humanidade atingir as pretensões iluministas de bem estar e libertação; o socialismo foi esta nova perspectiva, esse novo 'ponto de vista' de vivência do espaço relativo, de novas posições ideológicas e formas de se construir o espaço. Com o apoio das classes trabalhadoras em expansão nos diversos países, os partidos socialistas, sob a crença da inevitabilidade histórica de sua vitória, conforme a teoria de Marx e o 'progresso' iluminista, representou essa alternativa para os diversos Estados da Europa. Tornar-se-ia ela uma saída positiva e de estruturação libertária das dores da Guerra, uma possibilidade de ruptura voltada ao progresso (HOBSBAWN, 1995, p.62).

A relativização macroscópica foi acompanhada pela relativização microscópica na afirmação de uma realidade fundamentalmente processual, mas dessa vez com argumento definitivo à favor da presença das incertezas no mundo e conhecimento. Na física quântica, considerando o caráter fundamentalmente material e atômico de todos os objetos da natureza, inclusive dos aparelhos experimentais usados no laboratório, pode-se dizer que na interação entre o aparelho-sujeito e o átomo gera-se uma interferência que altera o estado do segundo. Esta situação produz as chamadas relações de incerteza o princípio da incerteza de Heisenberg de 1927 - das condições experimentais de localização objetiva (posição e velocidade) e de caracterização (onda/partícula) da partícula atômica, o elétron (HEISENBERG, 1981). A interpretação de Copenhague declara que as incertezas ontológicas (do objeto em si) e epistemológicas 
GOMES, R.D. \& VITTE, A.C. Geografia e complexidade pelas...

(do ato de conhecê-lo) encontradas não advinham da subjetividade do pesquisador, não eram ilusões. $\mathrm{Na}$ verdade, elas eram intrínsecas as próprias condições experimentais e, por isso, não poderiam ser consideradas como aparentes. A discussão diz o mesmo para o caráter complementar, atribuído por Niels Bohr, do dualismo descritivo para as propriedades do elétron, onda e partícula; ou seja, o elétron é 'outra coisa' do que uma onda ou uma partícula, já que estas propriedades são atribuídas somente mediante a escolha do sujeito, e método. Nesta situação o que é ontológico (existir) e o epistemológico (conhecer) fluem na relação; consideração que a Teoria da Complexidade vai corroborar no final do século XX. Comentam-se também aspectos como a quebra da causalidade, cuja situação acabou argumentando a favor da impossibilidade de experimentalmente definir-se por completo o estado de um sistema a partir do seu estado anterior ou posterior, de forma que não é possível aprovar ou desaprovar a hipótese de que o universo físico é causalmente conectado, resta sempre uma fundamental incerteza (MCKEEHAN, 1935, p.514). A situação encontrada na escala quântica requereu a elaboração de um 'modelo teórico' para adequar as descrições newtonianas para com a manifestação encontrada, cujo principal interpretação é a ortodoxa, a de Copenhague. Ou seja, diferente da idéia de que a ciência partia diretamente da realidade, mostrou-se que o átomo é 'diferente' e 'com grau de incerteza em relação à sua localização e propriedade' do que o modelo representa.

Lembra-se que no panorâma econômico da época a depressão que se estabeleceu dois anos depois do princípio da incerteza de Heisenberg colocava um forte sentimento de incerteza nas finanças, inclusive de incerteza no próprio modo de produção capitalista. Soma-se que no conhecimento científico-filosófico, Gödel em 1931 e Tarski em 1936 demonstraram que a lógica e a matemática não encontram fundamentos absolutos finais em si mesmos, ou seja, as principais ferramentas do raciocínio científico, antes tratadas como absolutas e também diretamente ligadas à realidade, também não poderiam mais afirmar de forma definitiva 
GOMES, R.D. \& VITTE, A.C. Geografia e complexidade pelas...

suas 'certezas'. No conhecimento científico, um dos principais aspectos à se destacar, deste primeiro 'pacote' de avanços, frentes aos objetivos aqui propostos, de realce das incertezas, é o reconhecimento do papel que a Teoria apresentou-se como mediadora indireta e incerta entre o conhecimento humano e a natureza, o mundo. O conhecimento deixou de ser pautados em principios absolutos e tornou-se fundamentalmente processual. Essa movimentação de entendimentos gerou, em conseqüência, a maior discussão epistemológica do século, com respeito, justamente à organização e evolução-transformação dessas teorias no sentido processual de um conhecimento e realidade, e que envolveram figuras com K.Popper, Kuhn, Lakatos, Feyerabend, Horton etc (LAKATOS \& MUSGRAVE, 1979, p. 343).

Hartshorne não realiza em seus escritos uma discussão entre o contexto científico-filosófico descrito e a Geografia, embora transpareça fluência acerca do 'método' científico ao discutir aspectos epistemológicos mais gerais (HARTSHORNE, 1978, p.155). Assim, não é possível avaliar quais as diretas influências deste contexto, em vista de, parece ser este o caso, ele mesmo não ter escrito nada respeito. Aproximações indiretas podem ser feitas em remetimento à, por exemplo, referências bibliografias de seus trabalho, contudo, o geógrafo americano, em seus dois maiores trabalhos sobre a natureza da Geografia, cita apenas, no The Nature in Geography, um livro do estado da arte da epistemologia da ciência do período, o Reason and Nature: an essay on the meagning of scientific method de Morris Cohen (1931). Pois bem, ainda assim, como era de se esperar, observa-se congruências entre a visão de Cohen e os argumentos de Hartshorne. O filósofo Morris Cohen é conhecido por tratar, a partir de leituras do historicismo, a consciência e fenômeno social como irredutíveis e distintos à causalidade física. Outro aspecto marcante das proposições de Cohen é tratar as polaridades pautadas no dual, como semelhança/diferença, unidade/pluralidade, processo/forma, como sendo ambas reais, 'caminhos para se chegar à natureza das coisas', havendo para ele, e Hartshorne o acompanha nisso, a necessidade de tolerar e dialogar pontos de vistas conflitantes para visões mais amplas. Conceber o 
GOMES, R.D. \& VITTE, A.C. Geografia e complexidade pelas...

diálogo entre as concorrências e as contradições também é um dos carros chefes da Teoria da Complexidade.

Embora tal referência já remeta à certa simpatização de idéias e consciência dos limites do universal-absoluto e inserção das incertezas, tal procedimento não é necessariamente o mais adequado para tais aproximações. Dessa forma, preferimos buscar nas passagens de discussões que Hartshorne realiza para responder às questões do período, elementos de congruência entre seus argumentos e a forma como entendimentos precursores da Teoria da Complexidade, como a Relatividade e Quantica estavam concebendo o mundo e o conhecimento. Mesmo destinadas à outros fins podemos retirar delas elementos ontológicosepistemológicos que possam mais diretamente ligar o seu pensamento e aproximar suas 'diferenciações de áreas' com o contexto de constituição da Teoria da Complexidade.

Para não esquecer do contexto de incerteza no imaginário da época convém lembrar que a Alemanha de Hitler invadiu a Polônia em 1 de Setembro de 1939, mês da publicação do The Nature of Geography, culminando nos 50 milhões de mortos da Segunda Guerra Mundial. O objetivo epistemológico de Hartshorne, ao contrário, era justamente afastar as incertezas e contradições dualísticas que pairava na Geografia e lembrar sua legítima posição entre as ciências. E é buscando atingir isso que deixa transparecer nas suas argumentações a consciência sobre os limites do conhecimento e princípios universais, principal sentido do realce das incertezas na ciência e sociedade da primeira metade do século.

Em diversas passagens Hartshorne deixa claro que carrega uma concepção não-absoluta acerca do universal, e coloca as incertezas como inerentes ao conhecimento. $\mathrm{O}$ universal fica sempre remetido ao seu sentido característico de generalidade, regularidade, de elaboração de conceitos genéricos, mas não de leis fixas e infinitas. Para explanação crítica toma o Determinismo como representante dessa concepção absoluta, e, parecendo defender as repercussões dos avanços descritos e da presença das incertezas no mundo e conhecimento, ele pergunta: 
GOMES, R.D. \& VITTE, A.C. Geografia e complexidade pelas...

“(...) podem as ações de seres humanos, como indivíduos, ser considerados como teoricamente determináveis por leis científicas inexoráveis e invariantes e, se assim for, podemos acaso esperar conhecer de maneira suficiente essas leis e os fatores condicionantes a ponto de sermos capazes de deduzir qual seja a sua ação, em casos específicos?" (HARTSHORNE, 1978, p.162).

Respondendo negativamente a questão, Hartshorne (1978, p.192) trata o determinismo científico a partir de seu sentido fatalista, e citando Chamberlin conclui que insistir com o determinismo (fatalista) é incoerente. Nesta discussão remete diretamente à Física Quântica, colocando que,

(...) os Físicos já haviam aprendido a viver ante a inexplicabilidade e a incerteza derradeira das ações dos elétrons individuais, os psicólogos e os especialistas em ciências sociais que jamais se aproximaram das certezas absolutas, não titubeia à colocar um nível de incerteza em suas descrições, mesmo que seja recorrendo à tese do livre arbítrio (HARTSHORNE, 1978, p.163).

Hartshorne (1978, p.163) lembra que o grau de incerteza será sempre menor que a incapacidade de determinar todas as causas para as ações humanas, ou seja, a falta do completo conhecimento que atribuiria o caráter de Lei para o comportamento humano em geral. Neste assunto Platt (1948, p.127-129) já havia lembrado que sempre, na Geografia, para o tratamento do humano haveria uma área crítica além do alcance analítico. Como já discutimos em outra ocasião, o determinismo foi vivido de diversas formas ao longo da história moderna da Geografia, e não necessariamente precisa ser interpretado e tratado em seu sentido fatalista, pois ainda apresenta-se como uma noção ampla que a Geografia pode utilizar-se para dialogar com as perspectivas abertas com a Complexidade e ajudar a romper com as amarras epistemológicas (DUTRA GOMES, 2009). 
GOMES, R.D. \& VITTE, A.C. Geografia e complexidade pelas...

Mas o que Hartshorne coloca é que para explicar uma única atitude e decisão humana a partir das leis da causalidade exigir-seia todo o conhecimento da herança biológica e sócio-cultural etc que o moldaram determinado sujeito desde sua infância, "dados muito superiores ao que jamais poderíamos obter" (HARTSHORNE, 1978, p.164). Conclui que a tese do determinismo é uma questão de convicção, crença, filosófica cujo problema não necessariamente apresenta relevância prática para a Geografia; embora não seja o caso de aprofundar a discussão, em relação à isso podemos dizer que ainda cabe relevar a possibilidade de uma releitura do determinismo frente a Teoria da Complexidade para ampliar o arcabouço dos modelos-práticos, e que é compartilhada por outros autores contemporâneos (DUTRAGOMES, 2009). De qualquer forma, sobre os limites do universalabsoluto, recorrendo ao livre-arbítrio, ou a impossibilidade de lhe dar com infinitos dados, coloca que,

(...) sempre haverá de permanecer "áreas ocultas" em qualquer campo das ciências sociais que não poderão ser explicada por leis científicas. (...) os princípios científicos deixarão de completar-se no ponto em que for necessário interpretar as motivações e as resultantes das decisões de pessoas individualmente, ou seja, um grande número de fenômenos, inclusive na temática da Geografia Física, não poderá ser explicado pelas leis da causalidade (HARTSHORNE, 1978, p.165).

Hartshorne lembra que a discussão não é recente, e que Wagner (1880) apud Hartshorne (1978) já havia colocado que a Geografia era uma parte das ciências naturais, que se utilizava de leis, mas essas leis não poderiam abranger o conteúdo da Geografia. Pois, apesar dos estudos de áreas individuais terem aumentado significativamente no final do XIX e primeira metade do século XX, isso não necessariamente permitiu a formulação de leis sobre as regiões. Mas lembrou que é um erro a opinião de que o objetivo da Ciência é descobrir leis, seria confundir os meios 
GOMES, R.D. \& VITTE, A.C. Geografia e complexidade pelas...

com os fins (HARTSHORNE, 1978, p.156-157). Critica tal sentido e coloca a necessidade de reconhecer as outras formas de conhecimento como legítimos e presentes; sentido convergente com os da Teoria da Complexidade nos dias atuais:

(...) embora os cientistas do século XIX confiantemente esperassem que todo o conhecimento da realidade seria em breve organizado segundo leis gerais, nenhum domínio logrou reduzir todos os seus resultados a esses termos, e não podemos prever que isso jamais seja possível (...) (1978, p.178); reconhece então que, (...) todos os campos que se denominam 'ciência' teriam, por conseguinte, de distinguir entre suas partes científicas e suas partes não científicas (...) de um lado a definição formal, de outro, a intuição, o bom senso, a percepção artísticas, o julgamento pessoal (1978, p. 179).

Não se tira, entretanto, a importância de se estabelecer regras, regularidades e disso, conceitos genéricos, ao contrário, são aspectos fundamentais do fazer científico, de forma que, "(...) nossa capacidade de analisar e interpretar as inter-relações dos fenômenos exige o emprego de conceitos genéricos" (HARTSHORNE, 1978, p.169).

Acrescenta:

O próprio fato da Geografia se preocupar em compreender as variações e inter-relações de um número ilimitado de lugares, cada qual constituídos de um complexo de um número quase ilimitado de elementos inter-relacionados, impõe-nos a necessidade de elaborar conceitos e princípios genéricos. (...) o que constitui uma vantagem primordial (...) empregando uma única palavra, ou frase, que designe o 'tipo' definido, somos capazes de dar uma descrição parcial de muitas espécimes individuais. (...) esses "universais"(...) oferecem os únicos meios para que uma interpretação de relações, num caso específico, possa ter um grau de fidedignidade superior ao de uma conjectura inteligente e perspicaz (HARTSHORNE, 1978, p.167). 
GOMES, R.D. \& VITTE, A.C. Geografia e complexidade pelas...

Contudo, advoga a paridade do nível particular, as diferenciações areais:

Apesar de muitas áreas do conhecimento não se perturbarem em reduzir os elementos individuais às médias estatísticas e desconsiderar, as diversas variações e incertezas (grifo nosso) quando tratados à nível particular, em muitos aspectos a ciência também se importa em saber se e compreender casos individuais (HARTSHORNE, 1978)

\section{Aproximações entre as transformações... o organizacional... a complexidade e Richard Hartshorne}

A física do não-equilíbrio é um dos principais ramos que influenciou a emergência do contexto da Complexidade. Interessa aqui que ela destacou o papel de agentes históricos que desempenham as bifurcações e a produção de entropia. Isso significa a quebra da simetria temporal, e, associados a emergência de processos organizacionais e criativos observados e estudados em laboratório, defendeu a existência de uma Flecha do Tempo que realça não somente os estados de equilíbrio e estabilidade, mas também as transformações e criatividade na Natureza, pelo surgimento e complexificação de novas estruturas espaçotemporais. Afirma-se que a instabilidade e criatividade são inerentes ao nosso mundo (PRIGOGINE, 1989, p.396).

Diferente da concepção newtoniana de Tempo universal externo aos corpos, agora o Tempo liga-se à vivência singular de cada sistemas (de relações) dinâmicos na natureza. Feitas num processo de interações espaciais consigo mesmo e o ambiente produz entropia e bifurcações, que, retroativamente, alimenta e compõe essas interações, e que tornam única a história de cada sistema de relações a todo instante e sua vida inteira, dos átomos às galáxias. Diferente da concepção kantiana que concebia o tempo ligado à experiência interna do sujeito, e fora dele nada seria, o Tempo ganha status ontológico, ligado tanto à uma vivência 
GOMES, R.D. \& VITTE, A.C. Geografia e complexidade pelas...

conjunta de 'queima' de entropia total e momentânea de todo o Universo, mas principalmente interno, de forma única à interação de cada sistema consigo mesmo e o ambiente. Dessa forma, o Tempo, ao mesmo instante, tanto nos uni a tudo na teia espaçotemporal, quanto nos distingue enquanto entidades singulares, cada um com sua própria temporalidade. $\mathrm{O}$ argumento de Hartshorne (1939, p.178) serve para transferir tal entendimento para o contexto geográfico: a landscape is not a whole that grows as a whole, but only as each part grows, so that "the history of a landscape becomes the histories of its parts".

Ao ganhar status ontológico o Tempo criativo torna-se condição para a existência de uma Natureza espaçotemporalmente tal qual como a experiênciamos. Onde as coisas possam 'brotar' e 'surgir' a partir dela mesma, se transformar e complexificar. Onde, diferente da ideia de mundo mecanicista-determinista, as coisas possam nascer e morrer, fazer-se e desfazer, inclusive o lúdico. $\mathrm{O}$ espaçotempo já fundidos, se mesclam na fluidez do processo organizacional, com o Tempo se ligando às interações espaciais e vice-versa. Tendo como uma das noções norteadoras a Autoorganização, por ela apresenta-se a constatação, a partir de experimentos científicos, de que a matéria poderia adquirir propriedades criativas, com emergência de estruturas espaçotemporais e, caso envolvesse um significativo número de componentes individuais estruturados, interagindo e co-existindo entre si, poderiam surgir espontaneamente comportamentos autônomos e coerentes em nível macroscópico, com novas propriedades e funcionalidades à nível de totalidade, como são os elementos atômicos, as moléculas, os minerais, as estrelas, os planetas, os furacões, a vida, as espécies, as casas, os bairros, as cidades, os países etc denominadas por Prigogine (1996) de estruturas dissipativas. Exploraremos a noção de autoorganização e sua relação com as diferenciações de áreas de Hartshorne em outra oportunidade.

A dinâmica destes sistemas auto-organizados, as estruturas dissipativas, não detinham somente aspectos fisicos-mecânicoscausais, mas também transferências de informação-sinais- 
GOMES, R.D. \& VITTE, A.C. Geografia e complexidade pelas...

comportamentais, que possibilitava o sistema mudar e se adaptar no ambiente, a partir de suas relações internas e externas. Isso realçou a não-redutibilidade de manifestação $e$ descrição no estudo de muitos fenômenos físicos e emergentes na natureza. $\mathrm{Ou}$ seja, contesta-se a possibilidade de reducionismos entre os multidomínios funcionais gerados. Eles são 'diferentes' um do outro em manifestação - ontológico - e entendimento - epistemológico. Sua descrição, pelo reconhecimento das diferenças, encontra-se, nestes termos, na encruzilhada complementar da distinção entre as formas de conhecimento nomotética e idiográfica, ou ainda, explicativo e interpretativo, e no caso para o estudo dos humanos, na encruzilhada entre as Ciências e Humanidades.

Ainda que sobre outros termos, a multiplicidade de níveis manifestação dos domínios, bem como a grande dificuldade de conjugá-los, parece constar em Hartshorne quando fala que:

O progresso dos conhecimentos exige autonomia de investigação em cada um dos três diferentes níveis da realidade - o inorgânico, o orgânico e o superorganico ou cultural. Dado que a Geografia agrupa os fenômenos (dos três níveis) em níveis díspares, "a descoberta das relações intercausais deve ser extremamente difícil” (1939,p.35).

O sentido do contexto da Complexidade, traz que os sistemas de relações são compostos por uma infinita gama de interações entre elementos, forças, domínios (esferas de ações) emergentes e dimensões não-redutíveis, nem em manifestação, nem em entendimento uns aos outros. As interações não-lineares podem advir de motivos distantes do local e ocasionar que pequenas causas podem gerar amplos efeitos no próprio sistema e no ambiente. Mas isso ocorrerá somente se as interações forem suficientemente ricas e amplas, com o objeto complexo detendo influências internas e externas advindo de forças não-locais. Hartshorne (1939, p.181) já havia observado tais complexidades de interações entre as áreas: 
GOMES, R.D. \& VITTE, A.C. Geografia e complexidade pelas...

When we consider a particular areal unit, or "individual landscape," however determined, there is the further major objection that the changes within it are not necessarily produced by its own forces, but may be caused by forces entering from other áreas. (...) The various forces that alter the landscape of an area, whether they are internal or external, recognize no common limits to the area.

Novamente frisando, a Teoria da Complexidade, por seu lado, tem como problema fundamental a incompletude do conhecimento (MORIN, 1985, p.62). Declara que é impossível a realização de um conhecimento total e monístico de qualquer sistema da natureza, em vista de sua não-redutível complexidade ontológica e epistemológica, além de nossa inevitável e irremediável limitação enquanto conhecedores reais e não transcendentais sob bases absolutas.

(...) o que seria uma epistemologia complexa? É não mais a existência de uma instância soberana, o epistemólogo que controla de maneira irredutível e irremediável todo o saber. Não existe trono soberano, mas pluralidade de instâncias. Cada uma dessas instâncias é decisiva; cada uma delas é insuficiente. Cada uma dessas instâncias comporta seu princípio de incerteza (MORIN \& LE MOIGNE, 2001, p.68).

Isso também não quer dizer desânimo em relação às metas científicas, em vista que, desde o período de Humboldt, a filosofia já trazia que a certeza e a completude não era o objetivo máximo do conhecimento. Sobre as dificuldades de atingir a completude na Geografia Hartshorne coloca que,

(...) a Geografia não pode abandonar a sua meta, qual seja, compreender, da melhor maneira possível, o complexo de fenômenos que existem inter-relacionados in situ. Conforme a conclusão de Humboldt, "ainda que a meta não seja atingível em sua totalidade, a solução parcial do problema, o esforço no sentido da compreensão dos fenômenos do mundo, continua a ser o mais elevado e eterno propósito de todas as pesquisas" (1978, p.172). 
GOMES, R.D. \& VITTE, A.C. Geografia e complexidade pelas...

Influenciado pela heterogeneidade do fenômeno geográfico Hartshorne bem expressa tal sentido da incompletude do conhecimento universal ao dizer que,

(...) busca reconhecer que a análise completa do "complexo total" não é praticável, como também não deve ser postulado como alvo teórico. Tal meta exigiria, até mesmo no estudo de pequena área, a análise de um número literalmente infinito de elementos incomensuráveis, e a publicação dos resultados de uma pesquisa não caberia numa estante de livros de metro e meio de altura (HARTSHORNE, 1978, p.39).

E convém citar a consciência de Hartshorne para com os limites das leis absolutas:

(...) embora os cientistas do século XIX confiantemente esperassem que todo o conhecimento da realidade seria em breve organizado segundo leis gerais, nenhum domínio logrou reduzir todos os seus resultados a esses termos, e não podemos prever que isso jamais seja possível (...) (HARTSHORNE, 1978, p.178).

E é justamente com base em tamanha heterogeneidade de entidades e forças que chega a uma forte conclusão, mas que, agora, segundo o problema fundamental da Complexidade, não justifica ter ele destacado a Geografia das outras ciências, inclusive das sistemáticas:

A Geografia é um campo cuja matéria inclui a maior complexidade de fenômenos, e, ao mesmo tempo, preocupa-se, mais do que a maior parte dos outros, com estudos de casos individuais - dos inumeráveis lugares do mundo e do caso impar do próprio mundo. Por estas duas razões 'a Geografia é menos capaz do que muitos outros domínios de elaborar e empregar leis científicas' (HARTSHORNE, 1978, p.180).

A perspectiva organizacional trazida pela Complexidade realça as propriedades organizacionais da matéria como veio 
GOMES, R.D. \& VITTE, A.C. Geografia e complexidade pelas...

fundamental para superar os reducionismos e convergir os entendimentos dos pares duais; conforme SPEDDING (1997, p.264), no campo da geomorfologia, já nos apresentava o desafio:

To redefine biology, or geomorphology, in terms of the study of organizational dynamics is to restore its natural context, which carries within it a critique of the established reductionist tendency in science. The weakness of classic reductionist method is that it is both aspatial and atemporal: thereby it denies the complexity of the real world it purports to explain.

Todo sistema físico é, assim, um vir-a-ser dependente do seu ambiente e submetido ao tempo, que não é apenas aquele que vai do nascimento à dispersão, mas também o da evolução $\mathrm{e}$ organização, com todos os sistemas da Natureza detendo a finitude (entropia) que antes era apenas reservada ao homem. Essas considerações físicas reintegram o sujeito no que Morin (2002, p.335) denomina physis renovada, ou seja, na Natureza que ele descreve, num naturalismo renovado como ser vivo desde Darwin, e agora, concebido enquanto máquina cibernética, associado ao universo das estruturas que dissipam energia (PRIGOGINE, 2002, 85p.). Assim, como já colocava Hartshorne (1978, p.71-74), mas à partir de sua experiência nos estudos geográficos,

"o homem pertence à Terra, é terrestre, (...) qualquer obra material do homem, quer seja uma casa, plantada no chão, uma fazenda ou uma cidade, constitui uma combinação de elementos naturais e culturais", assim, com salientou Hettner, "a natureza e o homem são absolutamente inseparáveis na complexa união que forma o caráter das áreas".

Há de se destacar que essa consciência atualmente destacada pela Teoria da Complexidade vem do campo das ciências físicas, que, na perspectiva sistêmica, realça o sujeito do conhecimento sem transcendê-lo à realidade física, mas emergindo dela como resultado de uma dinâmica complexa. Mesmo fornecendo um arcabouço que subjaz e associa os multi-domínios e dimensões da 
GOMES, R.D. \& VITTE, A.C. Geografia e complexidade pelas...

realidade, como histórico/causal, local/total, individual/coletivo, humano/natural essas considerações não dissolvem os antagonismos e as contradições presentes. Realça-se, ao contrário, a impossibilidade e a inadequação de se eliminar suas diferenças e singularidades de manifestação e entendimento. À este respeito, ao discutir se o estudo Geografia se restringia à fatos materiais, Hartshorne parece já conceber isso ao deixar claro que, no estudo dos fenômenos geográficos, mesmo pertencentes à mesma realidade total, existem diversos domínios - esferas de ações - de manifestação legítimos, e não-redutíveis um ao outro, inclusive de caráter emocional, e que também influenciam no entendimento dos lugares devendo ser estudados com os métodos adequados:

The immaterial phenomena are no less objective than the material objects. It is simply a problem of method to find objective means for observing them. When drought turned the wheat fields of the Great Plains into a "dust bowl," the widespread bankruptcy and the mental anguish of the farmers were facts no less objective than the number of inches of rainfall deficit for that summer or the decrease in humus content of the soil over many years (HARTSHORNE, 1939, p.195).

Com respeito a 'ciência' do espaçotempo, na esteira da Relatividade e Teoria Quântica, a concepção ganha significativos incrementos com os sistemas complexos. O próprio espaçotempo pode ser considerado como um processo auto-organizado (SMOLIN, 2003). O contexto que envolve o reconhecimento da historicidade pelas bifurcações, entropia etc pode ser tomado como referência que bem apresenta estes incrementos. Cabe então situar que se apresenta, então, os sistemas complexos, como os que compõem (e são compostos) a estrutura Espaçotemporal do Universo. Neste contexto, o reconhecimento da historicidade trouxe a consideração de união espaçotemporal de todos os corpos numa mesma momentânea produção total de entropia no universo, mas também, a diferenciação e discernimento de cada sistema, 
GOMES, R.D. \& VITTE, A.C. Geografia e complexidade pelas...

dimensões e domínios, dos átomos às galáxias, pela vivência espaçotemporalmente singular e única dessa queima de energia e inter-relações consigo mesmo e o ambiente. Ou seja, mesmo detendo regularidades, o universo também é permeado e se manifesta sempre de forma diferente e único em cada caso e instante - o fim das certezas (Prigogine, 1996, 199p.) -, as regras não são mais fundamentais que o singular, cada objeto (relações) também traz a sua particularidade, a sua diferenciação em relação ao restante de relações do Universo.

Ao pensar a Geografia como estudo das diferenciações de áreas Hartshorne (1939, p.181) parecia já conceber tais entendimentos de manifestações singulares mais ou menos autônomas ligadas às tensões de forças:

(...) that there is no unity of growth in the development of an area (or of a landscape), there is only a summation of partially related, but partially independent changes within it. The forces producing these changes-both the will and energy of the individual inhabitants and the changes in individual natural elements do not form a unit force, but merely a summation of more or less independent, often conflicting, forces.

A consideração trazida pela Complexidade, de que a Geografia trata fundamentalmente de particularidades geográficas-históricas, parece já ser notada nos argumentos de Hartshorne, e que acompanham essa concepção de mundo, onde o particular é visto como de caráter mais fundamental que a regra, a semelhança:

O teste final, em Geografia, é sem dúvida o estudo da complexidade máxima das variações de áreas sobre a terra. Se considerarmos apenas lugares muitos pequenos, escolhidos ao acaso ou mediante determinado critério de amostragem, a complexidade de cada um deles será tão multiforme e envolverá tantos elementos semi-independentes, que não poderemos esperar encontrar, e de fato não encontraremos, graus suficientes de similaridades global que permitam a elaboração de tipos 
GOMES, R.D. \& VITTE, A.C. Geografia e complexidade pelas...

genéricos. (...) cumpre reconhecer que não importa qual seja $o$ método de amostragem, na maioria dos casos os nossos lugares de proporções reduzidas não podem ser tratados como verdadeiras amostras de áreas maiores (1978, p.168-160). (...) E um exame mais atento revela que nunca são exatamente iguais (1978, p.16). Elas sempre se diferem.

O caráter histórico de rupturas (quebras de simetria) em relação ao passado, associado à produção de entropia no universo, são, então, uns dos principais entendimentos que corroboram o caráter espaçotemporalmente localizado vinculado a um sentido 'construtivo', de diferenciação, de Natureza. Ocorre a necessidade de se inserir o fator histórico não mais somente ligado ao sujeito (sociedades, indivíduos, culturas, lugares etc), mas também referente ao objeto, ou seja, toda a natureza física torna-se histórica e construtiva em relação ao futuro, com cada sistema de interações detendo a sua própria história e potencialidades (e superações). Para a geomorfologia, conforme Spedding (1997, p.264-265) destaca, esse entendimento é importante...:

(...) to restore the respectability of conceptual, qualitative methods and so free us from the position of feeling we have to apologize for the interpretative, historical character of our science (Frodeman, 1995). These characteristics follow directly from the fact that geomorphology, if we are to define it as the process-led study of landform development, is a spatially and temporally located science (grifo nosso), i.e. it deals with an open system in the realist sense of system closure.

Revertido para estudos da paisagem, o conselho de Hartshorne (1939) continua então válido:

If the particular objects of the science of geography are the concrete 'landscapes' of the world, then geography must study these objects, not only in terms of their present form and function, but also in terms of their genesis-their origin and evolution. 
GOMES, R.D. \& VITTE, A.C. Geografia e complexidade pelas...

Sobre o dinamismo espaçotemporal, considerando que a historicidade, a importância do passado e o futuro em aberto, representa o surgimento do diferente pela mudança (tempo), e que o diferente só pode surgir da interação de diferentes, o espaço (que também é o tempo), passa a ser pensado como a multiplicidade de possibilidades de existência e inter-relação da diversidade e diferença; parece que se aproximando da filosofia de Deleuze (Orlandi, 2005, 222p.). O Tempo tornando-se uma propriedade fundamental interna dos objetos, logo do espaçotempo da natureza, o Espaço passa a ser reconhecido como a coexistência da multiplicidade de sistemas de relações, da diferença, inclusive de possibilidades de inter-relações que constituem o tempo. Nestes termos, como lembra Massey (1999) o Tempo precisa do espaço para existir; provavelmente espaço e tempo nasceram juntos, e devem ser concebidos como uma só coisa, se dando ao longo de relações entre si que produz e constitui a ambos. Os 'eventos' (quebras de simetria, bifurcações etc), que expressam o resultado desta relação a todo instante, constitui a propriedade histórica e em constante renovação de possibilidades do objeto, detendo, com isso, o futuro como incerto, em constante construção. Neste espaço, diferentes histórias coexistem, modulam-se, afetam-se, de maneira tanto conflituosa quanto cooperativa. $\mathrm{O}$ espaço não é assim pré-existente aos corpos, estático e atravessado pelo tempo, mas relacional, no sentido que, relações e espaço/tempo, embora possam ser distinguidos pelo observador, são, tanto uma só coisa, quanto mutuamente constitutivos constantemente por rupturas, atividades e generatividades.

Os limites entre espaçotempo se tornaram apenas fatores de discernimento, e mesmos assim extremamente tênues, constituindo um erro de princípio não considerá-los como interpenetrados. A relação entre Geografia e História, no sentido amplo, de sentido de espaço e de sentido de tempo, precisa ser discutida por estes novos termos. Esse é todo um campo com novas interpretações, conceitos e abordagens à se construir em ultrapassagem às dicotomias. Os seguintes argumentos de Hartshorne, que parece já esperançava tal fluidez, servem como consciência do desafio posto: 
GOMES, R.D. \& VITTE, A.C. Geografia e complexidade pelas...

A complete combination of history and geography, in conclusion, would represent the complete integration of the areal and temporal variations of the world - it would be reality. But we have no conceivable way of constructing any form of motion picture presenting simultaneously all the changing features of even one region, even in outline. We are forced to distinguish between an historical and a geographical point of view, and in order to master the technique of either, we need to keep clearly in mind the distinction between the two.

\section{Considerações finais}

A relação Geografia e Complexidade pode ser construída a partir de diversas leituras e diálogos possíveis, e não parece adequado restringir os caminhos possíveis. Autores como Friedrich Ratzel e Milton Santos têm sido requeridos para a construção dessa relação. Nossa proposta foi a de utilizar-se de Richard Hartshorne para construir o contato. Várias congruências foram encontradas, tendo como principais 'panos de fundo' a postura pragmatista presente em Hartshorne e a referência da noção de diferenciações de áreas, ambas em convergência com os sentidos trazidos pela Teoria da Complexidade; no primeiro caso, da ciência muito voltada à resolução de problemas, e no segundo, dos fenômenos como sempre espaçotemporalmente singulares. A noção de diferenciações de áreas via Hartshorne já havia sido notada como pertinente para a construção da relação Geografia e Complexidade. As considerações de Hartshorne deixam transparecer a consciência das movimentações contextuais na sociedade e ciência do período, e que traziam entendimentos ligados às noções como incerteza, transformações, organizacional e complexidade; considerações que a Teoria da Complexidade, com importantes outros incrementos, veio destacar no final do XX. As discussões epistemológicas escritas por Richard Hartshorne servem, assim, como conversor de 
GOMES, R.D. \& VITTE, A.C. Geografia e complexidade pelas...

significados da Teoria da Complexidade para o tratamento do fenômeno geográfico e da forma de se conhecê-lo.

\section{Referências bibliográficas}

ABREU, A.A.A Teoria Geomorfológica e sua Edificação: Análise Crítica. Revista Brasileira de Geomorfologia, Ano 4, No 2 (2003) pp.51-67

ANSELMO, R.C. M.S., BRAY, S.C. A influência dos darwinismos sociais no pensamento geográfico brasileiro. Geografia, vol.26, n.01, 2001.

BACHELARD, G. Epistemologia. Rio de Janeiro: Zahar editores, 1977, 196p.

BARNES, T.J. Geographical intelligence: American geographers and research and analysis in the Office of Strategic Services 19411945. Journal of History Geography, 32, 2006, pp.149-168.

BARNES, T.J. Geography's underworld: The military-industrial complex, mathematical modelling and the quantitative revolution. Geoforum, 39, 2008, pp.03-16.

BERGÉ, P., POMEAU, Y., DUBOIS-GANCE, M. Dos ritmos ao caos. São Paulo: Editora da UNESP, 1996, 301pp.

CARVALHO, M. B. Geografia e Complexidade. p.67-131. SILVA, A.A.D., GALENO, A. Geografia: ciência do complexus: ensaios transdisciplinares. Porto Alegre: $2^{\mathrm{a}}$ Ed. Sulina, 2008, 336p.

CLAVAL, P. Géographie. Humanine et économique contemporaine. Paris: PUF Fondamental, Press universitaires de France, 1984, 442p. 
GOMES, R.D. \& VITTE, A.C. Geografia e complexidade pelas...

DUTRA-GOMES, R. Ontologia Sistêmica: construção do espaço. GEOUSP, 25, 2009, pp.109-122.

DUTRA-GOMES, R. Geografia e Complexidade: das diferenciações de áreas à Nova Cognição do Sistema TerraMundo. Tese de Doutorado, Instituto de Geociências, UNICAMP/Campinas, 2010, 258p.

DUTRA-GOMES, R. A matriz espacial moderna: das diferenciações de áreas de Hartshorne à Teoria da Complexidade: $O$ caso da expansão do aeroporto internacional de Viracopos/Campinas-SP. Campinas: RELATÓRIO FAPESP IG/UNICAMP, Maio de 2012, 368p.

HARTSHORNE, R. The Nature of Geography: A Critical Survey of Current Thought in the Light of the Past. Annals of the Association of American Geographers, Vol. 29, No. 3. Sep., 1939, pp. 173-412.

HARTSHORNE, R. The Nature of Geography: A Critical Survey of Current Thought in the Light of the Past (Conclusion). Annals of Association of American Geographers, Vol. 29, No. 4, Dec., 1939b., pp. 413-658.

HARTSHORNE, R. Excepcionalism in Geography re-examined. Annals of the Association of American Geographers, Vol.XLV, No.3, 1955, pp.205-244.

HARTSHORNE, R. Perspective on the nature of geography. Chigago, IL: R. MacNally, 1959, 201p.

HARTSHORNE, R. Propósitos e natureza da geografia. São Paulo: Editora Hucitec, 1978, 203p. 
GOMES, R.D. \& VITTE, A.C. Geografia e complexidade pelas...

HARVEY, D. A condição pós-moderna. Edições Loyola, 1992, 349 p.

HARVEY, F., WARDENGA, U. Richard Hartshorne's adaptation od Alfred Hettner's systems of geography. Journal of Historical Geography, 32, 2006, pp.422-440.

HEISENBERG, W. Física e Filosofia. Brasília: Ed. Universidade de Brasília, 1981, 149 p.

HEPPLE, L.W. Geography and the pragmatic tradition: The threefold engagement. Geoforum, 39, 2008, pp.1530-1541.

HOBSBAWN, E. Era dos Extremos. O breve século XX - 19141991. São Paulo: Companhia das Letras, 1995, 598p.

KERN, S. The Culture of Time and Space - 1880-1918. Cambridge, Massachusetts: Harvard University Press, 1983, 372p.

JAMES, P.E. All Possible Worlds. A history of Geographical Ideas. Indianapolis: New York: The Bobbs-Merrill Company, 1972, 622p.

JAPIASSU, H. Questões epistemológicas. Rio de Janeiro: Imago, 1981, 173p.

LAKATOS, I. MUSGRAVE, A. A crítica e o desenvolvimento do conhecimento. São Paulo: Ed. Cutrix: Ed. da Universidade de São Paulo, 1979, 343p.

LUKERMANN, F. The Nature of Geography: Post Hoc, Ergo Propter Hoc? p.53-68. In: ENTRIKIN, J. N., BRUNNM S. D. Reflections on Richard Hartshorne's The nature of Geography. Washington, DC: Association of American Geographers, 1989, $170 \mathrm{p}$. 
GOMES, R.D. \& VITTE, A.C. Geografia e complexidade pelas...

MALANSON, G.P. Considering Complexity. Annals of the Assoc. of Amer. Geogr., 89, 1999, pp.746-753.

MANSON, S.M., O' SULLIVAN,D. Complexity theory in the study of space and place. Environmental and Planning A, vol.38, 2006, pp.677-692.

MCKEEHAN L.W. Physical Indeterminacy and Philosophical Determinism. Science, New Series, Vol. 81, No. 2108, May, 1935, p. 514.

MEYER-ABICH, A. A Filosofia de Alexandre de Humboldt. Representante do "Holismo" de Schelling. Boletim Geográfico. Transcrições. n.167, ano XX, 1962, p.139-146.

MOREIRA, I.C. Os primórdios do caos determinístico. In: SILVEIRA, A. M., MOREIRA, I. C., MARTINS, R. C. FUKS, S. Caos, acaso e determinismo. Rio de Janeiro: Editora UFRJ, 1995, 252p.

MORIN, E. On the definition of complexity. pp.62-68. In: The Science and Praxis of Complexity. Contributions to the Symposium held at Montpellier, France, 9-11 May 1984, Ed. The United Nations University, 1985, 384pp.

MORIN, E. LE MOIGNE, J.L. A inteligência da complexidade. São Paulo: Ed. Peirópolis, 2000, 263p.

MARTIN, G.J. In Memorian: Richard Hartshorne, 1899-1992. Annals if the Association of American Geographers, 84 (3), 1994, p.480-492.

MASSEY, D. Space-time, "science" and the relationship between physical geography and human geography. Transactions of the Institute British Geographers, New Series, 24, 1999, p.261-276. 
GOMES, R.D. \& VITTE, A.C. Geografia e complexidade pelas...

ORLANDI, L.B.L. A diferença. Campinas: Editora da UNICAMP, 2005, 222p.

PORTUGALI, J. Complexity theory as a link between space and place. Environmental and Planning A, vol.38, 2006, pp.647-664.

PRIGOGINE, I. The philosophy of instability. Futures, August, 1989, pp.396-400.

PRIGOGINE, I. O fim das certezas. Tempo, caos e as leis da natureza. São Paulo: Editora da UNESP, 1996, 199pp.

PRIGOGINE, I. As leis do caos. São Paulo: Editora UNESP, 2002, 109pp.

SCIENCE, magazine. Complex Systems. Science, 2 April, Vol.284, Issue 5411, 1999, pp.1-212.

SMØLIN, L. The Self-organization of Space and Time. Philosophical Transactions: Mathematical, Physical and Engineering Sciences, Vol. 361, Nº1807, Self-Organization: The Quest for the Origin and Evolution of Structure. June 15, 2003, pp.1081-1088.

SPEDDING, N. On Growth and Form in Geomorphology. Earth Surface Process and Landforms, Vol.22, 1997, pp.261-265 